\title{
Effects of Simulated Dark Shipping on the Carbohydrate Status and Post-shipping Performance of Phalaenopsis
}

\author{
Jiunn-Yan Hou \\ Department of Horticulture, National Taiwan University, 1 Roosevelt Road Sec. 4, Taipei 10617, Taiwan \\ William B. Miller \\ Department of Horticulture, Cornell University, Ithaca, NY 14853 \\ Yao-Chien Alex Chang ${ }^{1}$ \\ Department of Horticulture, National Taiwan University, 1 Roosevelt Road Sec. 4, Taipei 10617, \\ Taiwan
}

\begin{abstract}
AdDitional INDEX wORDs. chilling injury, temperature acclimation, flower maturity stage, postharvest handling, moth orchid, postproduction

Abstract. Phalaenopsis is one of the most important ornamental crops and is frequently transported between continents. In this study, the effects of the duration and temperature of simulated dark shipping (SDS) and the temperature difference between cultivation greenhouses and shipping containers on the carbohydrate status and postshipping performance were investigated. With a prolonged SDS from 0 to 40 days at $20{ }^{\circ} \mathrm{C}$, the percentage of the vegetative Phalaenopsis Sogo Yukidian 'V3' plants with yellowed leaves increased from $0 \%$ to $50 \%$, and the total carbohydrate contents in the shoot and roots gradually decreased over time. Furthermore, roots had greater reductions in glucose and fructose concentrations than the shoot after 40 days of SDS. After 7 days of SDS, the youngest bud and the nearly open bud on blooming plants of Phalaenopsis amabilis were found to be the most negatively affected among flowers and buds of all stages. These buds had lower soluble sugar concentrations and flower longevities compared with those of unshipped plants. The results of a temperature experiment showed that yellowing of the leaves and chilling injury (CI) occurred in Phalaenopsis Sogo Yukidian 'V3' after 21 days of SDS at 25 and $15^{\circ} \mathrm{C}$, respectively, regardless of pre-shipping temperature acclimation. However, 10 days of acclimation at $25 / 20^{\circ} \mathrm{C}$ (day/night) before SDS reduced CI and reduced the time to inflorescence emergence. Higher accumulations of sucrose in the shoot and glucose and fructose in roots were found after 21 days of SDS at $15^{\circ} \mathrm{C}$ compared with those at 25 and $20^{\circ} \mathrm{C}$. In conclusion, the carbohydrate status of Phalaenopsis was positively related to the post-performance quality. A reduction in the commercial quality after SDS may be attributed to a decline in carbohydrates. The optimal temperature for long-term dark shipping is $20^{\circ} \mathrm{C}$, and we recommend providing 10 days of lower-temperature acclimation $\left(25 / 20^{\circ} \mathrm{C}\right)$ before shipping to enhance the chilling tolerance and to promote early spiking of Phalaenopsis plants.
\end{abstract}

Phalaenopsis is an important floriculture crop throughout the world. Production of potted Phalaenopsis is an expanding industry, and it is common for plants to be exported for finishing and resale in other countries. Growers in warm climates mass produce Phalaenopsis plants at high temperatures (e.g., 28 to $32^{\circ} \mathrm{C}$ day temperatures are commonly used by Taiwanese growers) to promote rapid growth during the vegetative period. Large quantities of mature plants ready for flower forcing with low temperature are exported to growers in cooler climates. Because Phalaenopsis exhibits crassulacean acid metabolism (Guo and Lee, 2006), plants can tolerate rather harsh shipping conditions (Hou et al., 2010; Wang, 2007). A recent trend is for ready-toforce plants to be shipped by sea to cooler locations for flowering. It typically takes up to 3 weeks to ship Phalaenopsis plants from Taiwan to the United States and Europe, generally at 18

Received for publication 2 May 2011. Accepted for publication 22 July 2011. We appreciate the financial support provided by the Council of Agriculture, Executive Yuan, Taiwan [96AS-1.2.1-ST-a1(4) and 97AS-1.2.1-ST-a1(3)]

This study is a portion of a thesis submitted by Jiunn-Yan Hou in partial fulfillment of the Master of Science degree requirements.

${ }^{1}$ Corresponding author. E-mail: alexchang@ntu.edu.tw. to $20{ }^{\circ} \mathrm{C}$ in complete darkness. Phalaenopsis plants undergo a drastic temperature decrease of more than $10^{\circ} \mathrm{C}$ when they are moved from the greenhouse to the shipping container.

Carbohydrates play important roles in shipping and postharvest tolerance of crops. Higher levels of carbohydrates before shipping reduced the sensitivity of Pelargonium hortorum cuttings to ethylene and reduced the degradation of chlorophyll and leaf senescence after shipping (Rapaka et al., 2008). Pelargonium cuttings maintained higher carbohydrates at 10 than $20^{\circ} \mathrm{C}$, which may contribute to reduce leaf senescence and to improve root formation (Druege and Kadner, 2008).

Net photosynthesis of Phalaenopsis plants is obviously inhibited during dark shipping but recovers within 1 week after removal from SDS (Hou et al., 2010). Therefore, investigations of carbohydrate changes in dark storage would be useful to understand how Phalaenopsis plants tolerate darkness for such long periods.

Exposure to low temperature results in CI to Phalaenopsis, symptoms of which include water-soaked spots on leaf surfaces and yellowing of the leaves; leaf drop occurs when the injury becomes more severe (McConnell and Sheehan, 1978; Wang, 2007). These symptoms are sometimes observed in Phalaenopsis 
plants after shipment (Wang, 2007). A dramatic temperature decrease between cultivation and shipping environments may also result in $\mathrm{CI}$. A protective effect of lower-temperature acclimation at $20{ }^{\circ} \mathrm{C}$ for $10 \mathrm{~d}$ against $\mathrm{CI}$ was reported for Phalaenopsis Atien Kaala 'TSC 22' in 10 d of simulated air-freight conditions, and that study also suggested increasing shipping temperatures from 15 to $25^{\circ} \mathrm{C}$ as the season changed from cold to warm (Wang, 2007).

Carbohydrate changes are also related to chilling tolerance; for instance, degradation of starches during fall and winter in many plants plays an important role in elevating their tolerance to chilling (Guy et al., 2008). Helianthus annuus leaves were reported to accumulate more glucose and fructose at $13{ }^{\circ} \mathrm{C}$ than at $30^{\circ} \mathrm{C}$ (Paul et al., 1991). Phalaenopsis accumulated higher level of soluble sugars after receiving 3 weeks of a low temperature $\left(20{ }^{\circ} \mathrm{C}\right)$ for flower forcing (Kataoka et al., 2004). However, temperature effects on the carbohydrate status during dark storage in Phalaenopsis have not been studied.

The objectives of this study were to determine the changes and allocations of carbohydrates in various organs of Phalaenopsis during simulated dark shipping and also their relationship with post-shipping performance. Furthermore, pre-shipping lower-temperature acclimation and various storage temperatures were applied to investigate how they would affect the plant carbohydrate status and post-shipping quality.

\section{Materials and Methods}

Plant materials. The white-flowered clone, Phalaenopsis Sogo Yukidian 'V3', purchased from Clone International Biotech Corp. (Pingtung, Taiwan), was used in Expt. 1 and Expt. 3. Plants with leaf spans of 32 to $37 \mathrm{~cm}$, which were mature and able to flower, were grown in $10.5-\mathrm{cm}$-diameter clear, softplastic pots $(0.75 \mathrm{~L})$ tightly packed with sphagnum moss. In Expt. 2, blooming $P$. amabilis were purchased from Taiwan Sugar Corp. (Nantou, Taiwan). The blooming plants were grown in 10.5-cm-diameter pots with sphagnum moss medium and bore a single inflorescence with 12 to 14 unopened floral buds. All plants were fertigated as needed with a water-soluble $20 \mathrm{~N}-8.6 \mathrm{P}-$ 16.6K fertilizer (Peters Professional 20-20-20; Scotts, Marysville, $\mathrm{OH})$ at $200 \mathrm{mg} \cdot \mathrm{L}^{-1} \mathrm{~N}$. Fertigation was stopped $\approx 7 \mathrm{~d}$ before SDS to reduce the risk of disease occurrence. Heating and cooling in the greenhouse were programmed to maintain average day/night temperatures of $28 / 25^{\circ} \mathrm{C}$, whereas automatic double-shaded cloth adjustment maintained a maximum photosynthetic photon flux $(P P F)$ of $370 \mu \mathrm{mol} \cdot \mathrm{m}^{-2} \cdot \mathrm{s}^{-1}$.

Simulated DARK ShiPPING CONDitions. Plants designated to receive SDS (hereafter referred to as "shipped plants") were put into corrugated fiberboard cartons with shredded newspapers and placed in a dark growth chamber at the designated temperatures and durations. The relative humidity was $40 \%$ to $50 \%$ in the cartons during storage, as measured by a data logger (H08-004-02; Onset, Buzzards Bay, MA).

Carbohydrate analysis. Plant parts were separated as described subsequently. Samples were then frozen in liquid nitrogen and stored at $-70^{\circ} \mathrm{C}$. After freeze-drying, dry weight was recorded, and then the samples were ground to a powder.

Each sample $(50 \mathrm{mg})$ was extracted at $70{ }^{\circ} \mathrm{C}$ with $3 \mathrm{~mL} 80 \%$ ethanol for $30 \mathrm{~min}$. One milligram of raffinose was added to each sample as the internal standard. After extraction, the tissue suspension was centrifuged at $4000 g_{n}$ for $10 \mathrm{~min}$ to collect the supernatant. Each sample was re-extracted twice, and the three supernatants were pooled. The pooled supernatants were deionized by passing through columns with $1 \mathrm{~mL}$ of cation resin (Dowex-50W, hydrogen form; Sigma, St. Louis, MO) and $1 \mathrm{~mL}$ of anion resin (Amberlite IRA-167, acetate form; Sigma). Samples were then reduced in volume in a vacuum concentrator (Rapidvap Vacuum Evaporation System; Labconco, Kansas City, MO) to less than $1 \mathrm{~mL}$ and diluted to $10 \mathrm{~mL}$ with high-performance liquid chromatography (HPLC)-grade water. After filtration $(0.22 \mu \mathrm{m})$ and appropriate dilution, samples were subjected to high-performance anion exchange chromatography (Dionex, Sunnyvale, CA) with pulsed amperometric detection (ED50; Dionex) equipped with a Carbopac PA-1 column (CarboPac ${ }^{\mathrm{TM}}$ PA1 Analytical, $4 \times 250 \mathrm{~mm}$; Dionex). Carbohydrates were eluted with $100 \mathrm{mM} \mathrm{NaOH}$ at a flow rate of $1.0 \mathrm{~mL} \cdot \mathrm{min}^{-1}$ for $20 \mathrm{~min}$. The separated carbohydrates (glucose, fructose, and sucrose) were quantified by comparison with known standards. The total soluble concentration was calculated from sum of the glucose, fructose, and sucrose concentrations.

The residue from the ethanol extraction was reserved for the starch analysis. Thirty milligrams of starch (Merck, Darmstadt, Germany) was used as the external standard. The residues were gelatinized at $100{ }^{\circ} \mathrm{C}$ for $6 \mathrm{~h}$ and then were dried at $60{ }^{\circ} \mathrm{C}$ in the oven. Each dried sample was suspended in $3 \mathrm{~mL}$ of enzyme solution and incubated at $37^{\circ} \mathrm{C}$ for $6 \mathrm{~h}$ and $55^{\circ} \mathrm{C}$ for $18 \mathrm{~h}$. The enzyme solution used Na-citrate buffer ( $\mathrm{pH} 4.5)$ as the solvent and contained pullulanase (3 units/sample; Sigma), amyloglucosidase (10 units/sample; Sigma), and $\alpha$-amylase (100 units/ sample; Type II-A; Sigma). After incubation, samples were filtered and diluted to $10 \mathrm{~mL}$ with HPLC-grade water. The subsequent procedure was similar to that of the soluble sugar analysis described previously. The amount of starch was determined by the glucose released after adjusting to an external standard.

The contents of glucose, fructose, sucrose, total soluble sugar, and starch in organs were calculated from multiplying their concentrations by dry weight of the organs.

EXPT. 1: Changes IN CARBOHYDRATES DURING LONG-TERM DARK STORAGE. Vegetative plants were placed in a phytotron with day/night temperatures of $30 / 25{ }^{\circ} \mathrm{C}$ and a natural light intensity of 300 to $400 \mu \mathrm{mol} \cdot \mathrm{m}^{-2} \cdot \mathrm{s}^{-1} P P F$ for $7 \mathrm{~d}$ before SDS began. They were then divided into five groups and subjected to SDS at a constant $20^{\circ} \mathrm{C}$ for $0,10,20,30$, or $40 \mathrm{~d}$. The first group (i.e., 0 d SDS) was not subjected to SDS and was directly sampled before SDS. After completion of each storage duration, the dry weight and percentage of plants with yellowed leaves were determined. Plants were then divided into two parts: the shoot included all leaves and the compressed stem, and the roots included all roots remaining on the stem. From these, the concentrations of glucose, fructose, sucrose, total soluble sugar, and starch were determined. Each treatment had seven singleplant replications.

EXPT. 2: EFFECTS OF DARK STORAGE ON THE CARBOHYDRATE StATUS OF BLOOMing PlANTS. Phalaenopsis amabilis plants, each with an inflorescence, were used in this experiment. Plants were placed in the greenhouse mentioned previously until they reached a suitable stage of flowering maturity (approximately five flowers opened on an inflorescence). Before dark storage, notations of floral maturity were made at an inflorescence as a unit. First, the nearly opened bud was marked as F 0, which was also used as a datum point. Counting from that point, younger buds were sequentially labeled F-1, F-2, F-3, etc., and older flowers were labeled $\mathrm{F}+1, \mathrm{~F}+2, \mathrm{~F}+3$, etc. After labeling, plants 
were placed in a dark growth chamber at $20{ }^{\circ} \mathrm{C}$ for $7 \mathrm{~d}$. Plants not receiving SDS and that remained in the greenhouse were used as the controls. Flower longevity and the carbohydrate status of plants were determined after completing SDS. Flower longevity was calculated as the duration in days between flower opening and wilting. Sampling for the carbohydrate analysis was conducted on the day SDS ended. The sampled parts included the newly matured leaf (the second leaf from the apex), F+4, F+2, F 0, F-2, F-4, F-6, and F-8. There were seven single-plant replications for the carbohydrate analysis and five single-plant replications for the flower longevity investigation in each treatment.

EXPT. 3: EFFECTS OF LOWER-TEMPERATURE ACCLIMATION BEFORE SHIPPING AND STORAGE TEMPERATURES ON THE CARBOHYDRATE STATUS AND SUBSEQUENT PLANT PERFORMANCE. Vegetative plants were grown at a phytotron with day/night temperatures of $30 / 25^{\circ} \mathrm{C}$ and a natural light intensity of 200 to $300 \mu \mathrm{mol} \cdot \mathrm{m}^{-2} \cdot \mathrm{s}^{-1} \mathrm{PPF}$ for $10 \mathrm{~d}$ to mimic the growing conditions in commercial greenhouses and then were divided into six groups of 12 plants each (as shown in Table 1). Temperature acclimation was done by transferring the plants to a $25 / 20{ }^{\circ} \mathrm{C}$ (day/night) phytotron with the similar light intensity for $10 \mathrm{~d}$ before SDS, whereas non-acclimated plants were kept at the original $30 / 25^{\circ} \mathrm{C}$ phytotron during that period. Both temperature-acclimated and non-acclimated groups were subjected to SDS at 25,20 , or $15^{\circ} \mathrm{C}$ for $21 \mathrm{~d}$. At the end of SDS, the number of yellowed leaves per plant was counted. A leaf with obvious yellow coloration or with yellowing at the base was defined as a "yellowed leaf." The degree of CI was determined using a scale from 0 through 3 by the following criteria: $0=$ no CI; $1=$ slight water-soaked spots on the leaf surface, reversible after subsequent growth; 2 = one leaf with a yellow spot; 3 = two or more leaves with obvious yellow spots, which covered more than $20 \%$ of the leaf areas. At the end of SDS, the plants were grown at day/night temperatures of 25/20 ${ }^{\circ} \mathrm{C}$, and the time to spiking (i.e., inflorescence emergence) was recorded.

Statistical ANAlysis. Data were subjected to an analysis of variance using a completely randomized design. Significance of

Table 1. Effects of pre-shipping lower-temperature acclimation for $10 \mathrm{~d}$ at $25^{\circ} \mathrm{C}$ day $/ 20^{\circ} \mathrm{C}$ night and the temperature of simulated dark shipping on subsequent leaf condition and the degree of chilling injury (CI) of Phalaenopsis Sogo Yukidian 'V3'. '

\begin{tabular}{lccc}
\hline $\begin{array}{l}\text { Storage } \\
\text { temp }\left({ }^{\circ} \mathrm{C}\right)\end{array}$ & $\begin{array}{c}\text { Temp } \\
\text { acclimation }\end{array}$ & $\begin{array}{c}\text { Yellowed leaves } \\
\text { (no. per plant) }\end{array}$ & $\begin{array}{c}\text { Degree } \\
\text { of } \mathrm{CI}^{\mathrm{y}}\end{array}$ \\
\hline 25 & No & 0.6 & 0.0 \\
& Yes & 0.6 & 0.0 \\
20 & No & 0.1 & 0.1 \\
& Yes & 0.0 & 0.0 \\
15 & No & 0.2 & 2.1 \\
& Yes & 0.1 & 1.3 \\
Significance & & $* *$ & $* * *$ \\
Storage temp (ST) & & NS & $*$ \\
Temp acclimation (TA) & NS & $*$ \\
TA $\times$ ST & &
\end{tabular}

Treated plants were stored in a cooler for $21 \mathrm{~d}$.

${ }^{\mathrm{y}} 0=$ no CI; 1 = slight water-soaked spots on the leaf surface, reversible after subsequent growth; 2 = one leaf with a yellow spot; $3=$ two or more leaves with obvious yellow spots, which covered more than $20 \%$ of the leaf areas.

NS, *,**,***Non-significant or significant at $P \leq 0.05,0.01$, and 0.001 , respectively; $\mathrm{n}=12$. linear and quadratic regressions between storage durations and carbohydrate concentration was calculated. Separation of means between treatments was determined with the Fisher's protected least significant difference test at $P \leq 0.05$. Statistical analyses were performed with Costat (Version 6.1; CoHort Software, Monterey, CA).

\section{Results}

Expt. 1: Changes in CARbohydrates during LONG-TERM DARK STORAGE. The percentages of plants with yellowed leaves were $0 \%, 0 \%, 20 \%, 30 \%$, and $50 \%$, respectively, after $0,10,20$, 30 , and $40 \mathrm{~d}$ of SDS (data not shown), which indicated a reduction in post-shipping quality with a prolonged shipping duration. The dry weights of the shoot and roots did not show significant change during the $40 \mathrm{~d}$ of SDS; only a slight reduction (9\%) was found in the shoot after $40 \mathrm{~d}$ of SDS (data not shown).

Changes in carbohydrates during the $0,10,20,30$, and $40 \mathrm{~d}$ of SDS were investigated in the shoot and roots. In the shoot, the glucose and fructose concentrations exhibited a linear reduction with storage time within $40 \mathrm{~d}$ of SDS. In more detail, we found that the concentrations of glucose and fructose remained stable during the first $20 \mathrm{~d}$ of SDS (Fig. 1A-B) and then gradually decreased by Day 40 by $32 \%$ and $24 \%$, respectively, of their

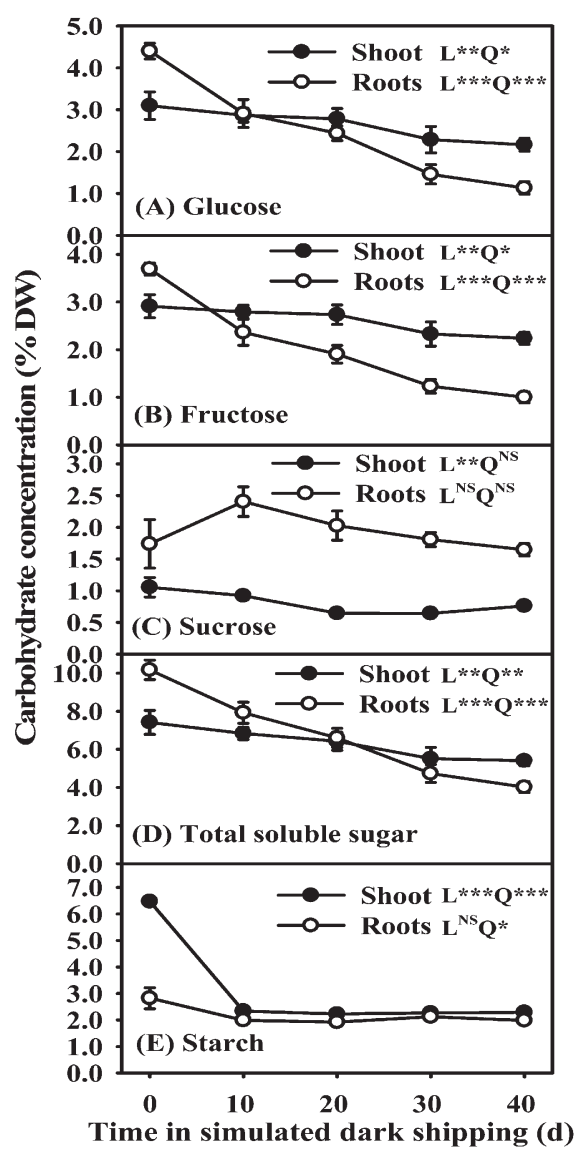

Fig. 1. Changes in glucose (A), fructose (B), sucrose (C), total soluble sugar (D), and starch (E) concentrations in Phalaenopsis Sogo Yukidian 'V3' during 0, $10,20,30$, or $40 \mathrm{~d}$ of dark storage at $20^{\circ} \mathrm{C}$. "L" and " $\mathrm{Q}$ " refer to linear and quadratic regression, respectively; $\mathrm{Ns}, *, * *$, and $* * *$ indicate non-significant or significant at $P \leq 0.05,0.01$, and 0.001 , respectively; bars indicate the SE $(n=7)$. 
initial levels on Day 0 (calculated from Fig. 1A-B). The sucrose concentration decreased with prolonged storage durations (Fig. 1C) with a $39 \%$ drop from Day 0 to Day 20 of SDS (calculated from Fig. 1C). The total soluble sugar concentration showed a $26 \%$ reduction on Day 30 compared with unshipped plants (calculated from Fig. 1D). A substantial reduction in the starch concentration was noted after $10 \mathrm{~d}$ of SDS with a $65 \%$ drop compared with Day 0 (calculated from Fig. 1E). Starch then remained in a low range of $2.2 \%$ to $2.3 \%$ dry weight for the duration of SDS (Fig. 1E). Additionally, the relationship between carbohydrate content and storage duration was similar to that of their concentrations as a result of the unchanged dry weights (data not shown). The total carbohydrate content decreased substantially in the first $10 \mathrm{~d}$ of SDS, mainly the result of starch breakdown, and gradually declined thereafter (Fig. $2 \mathrm{~A})$. At the end of the $40 \mathrm{~d}$ SDS, there was a $51 \%$ reduction in the total carbohydrate content compared with values in unshipped plants (calculated from Fig. 2A). In brief, shoot glucose and fructose concentrations remained stable in the first $20 \mathrm{~d}$ of SDS but slightly decreased thereafter (Fig. 1A-B). The starch concentration significantly decreased in the first $10 \mathrm{~d}$ and remained at a low level in the rest of the period during the $40 \mathrm{~d}$ SDS (Fig. 1E).

In roots, glucose and fructose concentrations decreased with prolonged dark storage (Fig. 1A-B) and exhibited $75 \%$ and $76 \%$ reductions on Day 40 of SDS, respectively, compared with unshipped plants (calculated from Fig. 1A-B). However, no specific relationship between sucrose concentrations and storage duration was found during this period (Fig. 1C). The total soluble sugar concentration decreased $61 \%$ by Day 40 (calculated from Fig. 1D). Breakdown of starch was observed in the first $10 \mathrm{~d}$ of SDS, and the starch concentration remained stable until the end of SDS (Fig. 1E). The total carbohydrate content considerably decreased in the first $10 \mathrm{~d}$ of SDS as a result of reductions in starch, glucose, and fructose (Fig. 2B) and de-

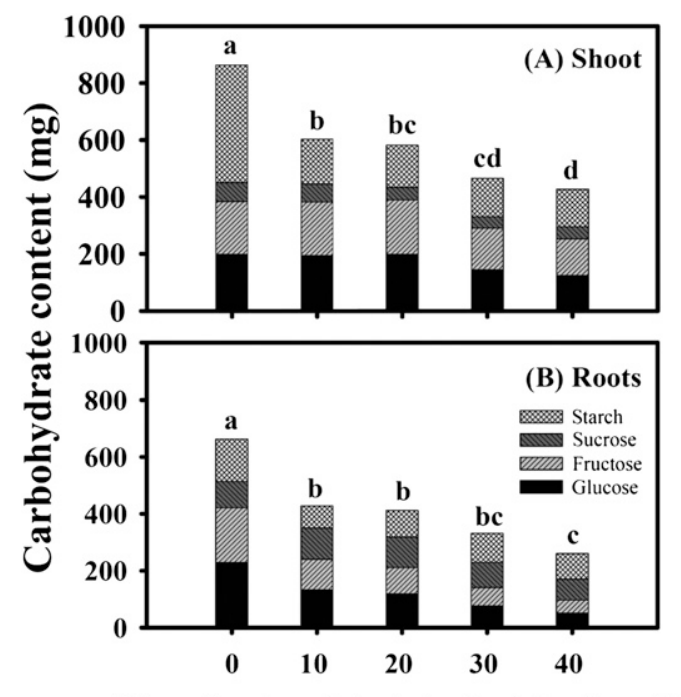

Time in simulated dark shipping (d)

Fig. 2. Changes of total carbohydrate contents in the shoot (A) and roots (B) of Phalaenopsis Sogo Yukidian 'V3' during 0, 10, 20, 30, or $40 \mathrm{~d}$ of dark storage at $20{ }^{\circ} \mathrm{C}$. Total carbohydrate is presented by the sum of glucose, fructose, sucrose, and starch contents. Columns, referred to the total carbohydrates, in the same graph marked with the same letter do not statistically differ at $P \leq$ 0.05 by least significant difference $(n=7)$. creased gradually thereafter (Fig. 2B). In summary, root glucose and fructose concentrations substantially decreased over the $40 \mathrm{~d}$ of SDS, but sucrose did not.

Before the dark storage (Day 0), ratio of the starch content to the total soluble sugar content in shoot was 0.94 , higher than in roots, 0.27 ( $P<0.001$ by $t$ test, calculated from Fig. $2 \mathrm{~A}-\mathrm{B})$; this observation indicated that the shoot conserved more carbohydrates in a storage form than did the roots. The result showed that leaves of Phalaenopsis served as the major source of carbohydrates in dark storage. However, the reduction of total carbohydrate content in the whole plant on Day 40 after SDS was partitioned nearly evenly (52\% loss in shoots and $48 \%$ loss in roots, calculated from Fig. 2A-B). Therefore, the carbohydrates in roots should also be important to post-shipping performance in Phalaenopsis.

EXPT. 2: EFFECTS OF DARK STORAGE ON THE CARBOHYDRATE STATUS OF BLOOMING PLANTS. Stages of flower maturity were labeled before the 7-d SDS. It is important to note that floral bud development was delayed by SDS, which resulted in the shipped plants having approximately one fewer opened flowers than control plants after $7 \mathrm{~d}$ of SDS (data not shown). However, the following data analysis was still based on the marks made before shipping.

Samples for the carbohydrate analysis were taken immediately after plants were moved out of SDS. In unshipped plants, the second leaf had lower concentrations of glucose, fructose, and total soluble sugar but a higher concentration of starch than opened flowers (Figs. 3A, 3B, 3D, and 3E). Concentrations of glucose, fructose, and total soluble sugar in floral buds rapidly increased with increasing age and gradually decreased after opening (Figs. 3A, 3B, and 3D). The sucrose concentration did not show a specific trend between various flower maturities (Fig. $3 \mathrm{C})$. A different trend was found for the starch concentration, which was highest in F-8 and decreased with bud growth until the nearly open stage (F 0) (Fig. 3E). These results showed that floral buds accumulated high concentrations of starch at the beginning of the developmental process (Fig. 3E). The starch then gradually degraded to glucose and fructose during the development process (Figs. 3A, 3B, and 3E). After a flower was fully open, the total soluble sugar concentration in the flower reached its maximum and then slightly decreased with increasing age (Fig. 3D).

In shipped plants, sucrose, total soluble sugar, and starch concentrations of the second leaf were lower compared with those of unshipped plants (Fig. 3C-E). Reductions in glucose and fructose concentrations were found in F 0 and F-2 (Fig. $3 \mathrm{~A}-\mathrm{B})$; reductions in sucrose concentrations were observed in the second leaf, $\mathrm{F}+4$, and $\mathrm{F}-8$ (Fig. 3C); reductions in starch concentrations were found in the second leaf and $\mathrm{F}+4$ (Fig. 3E). Except for starch, trends of glucose, fructose, and total soluble sugar contents at various flower maturity stages were similar to their concentrations (Figs. 3A, 3B, 3D, 4A, $4 \mathrm{~B}$, and 4D). Starch contents were lower in younger buds as a result of their lower dry weight (Fig. 4E).

On the day of completion of SDS, no plants had wilted buds or flowers (data not shown). However, 33\% of shipped plants showed flower bud abortion at F-8 (the youngest stage) $5 \mathrm{~d}$ after removal from storage (data not shown). Dark storage for $7 \mathrm{~d}$ reduced subsequent flower longevity of a blooming Phalaenopsis, and the most severe reductions occurred for F 0 and F-2 (Fig. 5).

As a result, the effect of dark storage on flower longevity varied with the age of flowers. The more mature (F 0 and F-2) and the youngest (F-8) floral buds were the most susceptible to 


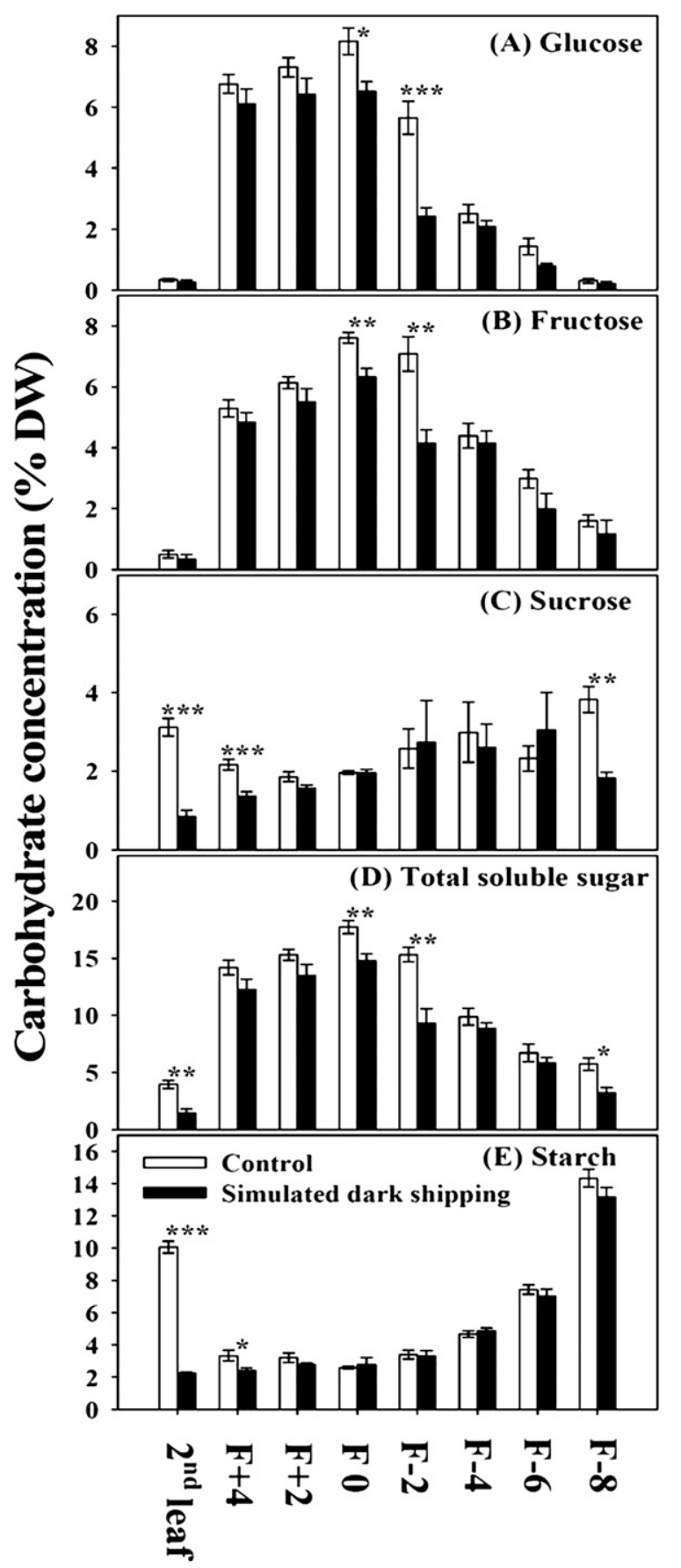

\section{Organs}

Fig. 3. Changes in glucose (A), fructose (B), sucrose (C), total soluble sugar (D), and starch (E) concentrations in Phalaenopsis amabilis after $7 \mathrm{~d}$ of simulated dark shipping at $20{ }^{\circ} \mathrm{C}$. Controls were not shipped and were grown in a greenhouse. F+4, F 0, and F-8 are a fully open flower, nearly open floral bud, and the youngest bud, respectively, before simulated dark shipping. The second leaf refers to a newly matured leaf (the second leaf from the apex). Bars indicate the SE $(n=7)$; columns marked with an asterisk indicate significant differences between treatments by least significant difference; *, **, and *** indicate $P \leq 0.05,0.01$, and 0.001 , respectively.

dark storage; consequently, shorter flower longevity and flower bud abortion were observed.

EXPT. 3: EFFECTS OF LOWER-TEMPERATURE ACCLimation BEFORE SHIPPING AND STORAGE TEMPERATURES ON THE

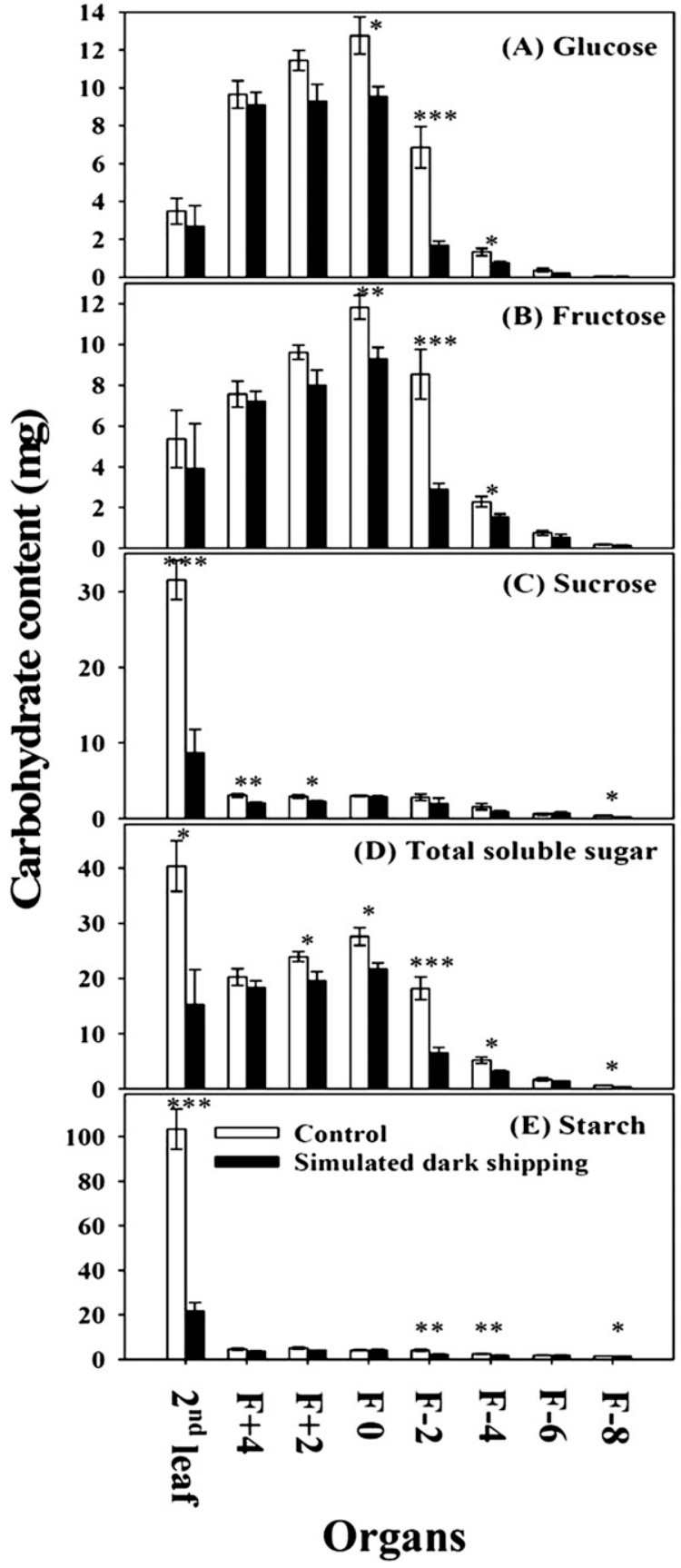

Fig. 4. Changes in glucose (A), fructose $(\mathbf{B})$, sucrose $(\mathbf{C})$, total soluble sugar (D), and starch (E) contents in Phalaenopsis amabilis after $7 \mathrm{~d}$ of simulated dark shipping at $20^{\circ} \mathrm{C}$. Controls were not shipped and were grown in a greenhouse. F+4, F 0, and F-8 are a fully open flower, a nearly open floral bud, and the youngest bud, respectively, before simulated dark shipping. The second leaf refers to a newly matured leaf (the second leaf from the apex). Bars indicate the SE $(n=7)$; columns marked with an asterisk indicate significant differences between treatments by least significant difference; $*, * *$, and $* * *$ indicate $P \leq$ $0.05,0.01$, and 0.001 , respectively.

CARBOHYDRATE STATUS AND SUBSEQUENT PLANT PERFORMANCE. The number of yellowed leaves did not differ between acclimated and non-acclimated plants; however, it was affected by storage temperatures (Table 1). Plants stored at $25^{\circ} \mathrm{C}$ had the highest number of yellowed leaves, whereas no difference was found between plants stored at 20 and $15^{\circ} \mathrm{C}$ (Table 1). After storage at $15^{\circ} \mathrm{C}$, plants suffered from CI whether they had been 


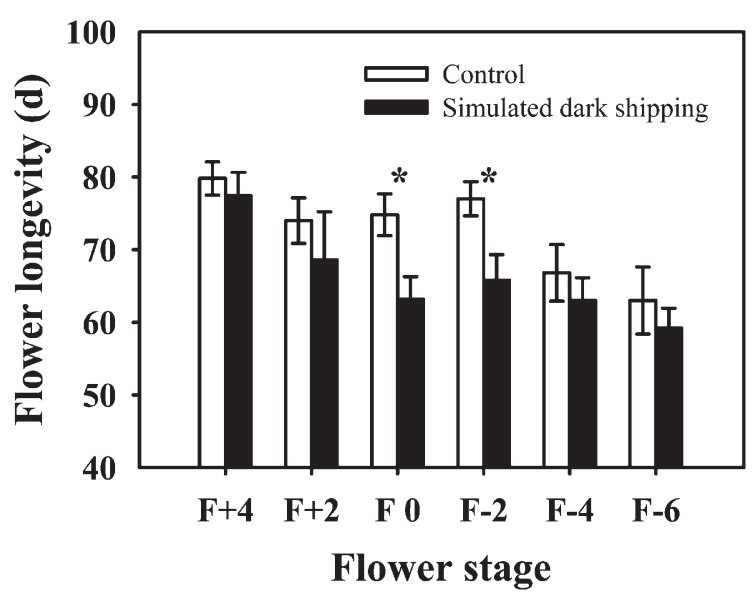

Fig. 5. Effect of $7 \mathrm{~d}$ in simulated dark shipping at $20^{\circ} \mathrm{C}$ on flower longevity of blooming Phalaenopsis amabilis at various floral developmental stages. Controls were not shipped and grown in a greenhouse. F+4, F 0, and F-6 are a fully open flower, a nearly open floral bud, and the younger bud, respectively, before simulated dark shipping. Bars indicate the SE $(n=5)$; columns marked with an asterisk indicate significant differences between treatments by least significant difference; $*$ indicates $P \leq 0.05$.

acclimated or not, but less severe CI was observed in plants with lower-temperature acclimation (Table 1).

Pre-shipping temperature acclimation had no effect on either shoot or roots carbohydrates after the 21-d SDS (Fig. 6). In the shoot, a higher sucrose concentration was found in plants stored at $15{ }^{\circ} \mathrm{C}$ (Fig. 6C). Concentrations of glucose, fructose, total soluble sugar, and starch did not differ among the plants regardless of pre-shipping temperature acclimation or storage temperatures (Figs. 6A, 6B, 6D, and 6E). In the roots, higher values of glucose, fructose, and total soluble sugar concentrations were observed in plants stored at $15{ }^{\circ} \mathrm{C}$ (Figs. 6F, 6G, and 6I).

With regard to flowering quality, a lower temperature acclimation before shipping reduced the time required for inflorescence emergence. For example, after $21 \mathrm{~d}$ of storage at $20^{\circ} \mathrm{C}$ and subsequent low-temperature forcing, acclimated plants required $18.0 \mathrm{~d}$ to spike compared with $24.5 \mathrm{~d}$ for non-acclimated plants (data not shown).

In summary, Phalaenopsis stored at $15{ }^{\circ} \mathrm{C}$ for $21 \mathrm{~d}$ had a higher degree of CI than those stored at 20 and $25^{\circ} \mathrm{C}$. Lowertemperature acclimation $\left(25^{\circ} \mathrm{C}\right.$ day $/ 20^{\circ} \mathrm{C}$ night for $\left.10 \mathrm{~d}\right)$ before SDS did not affect the carbohydrate status of Phalaenopsis plants after SDS but could alleviate the occurrence of $\mathrm{CI}$ and reduce the time to spiking.

\section{Discussion}

In our study, shoots of vegetative Phalaenopsis plants had higher starch concentrations but lower concentrations of soluble sugars than roots before SDS (Fig. 1). Starch is one of the storage forms of carbohydrates in plants (Theron and Jacobs, 1996). Phalaenopsis aphrodite was determined to be a starchforming species based on the type of carbohydrate reservoir used in its daily cycle: starch accumulates in the day and breaks down to form malate at night (Chen et al., 2008). Phalaenopsis roots are thick and succulent, and some contain chlorophyll and are thus capable of photosynthesizing (Motomura et al., 2008). Although the roots may act as a storage organ, the higher ratio of starch versus soluble sugars in shoot than in roots indicated that

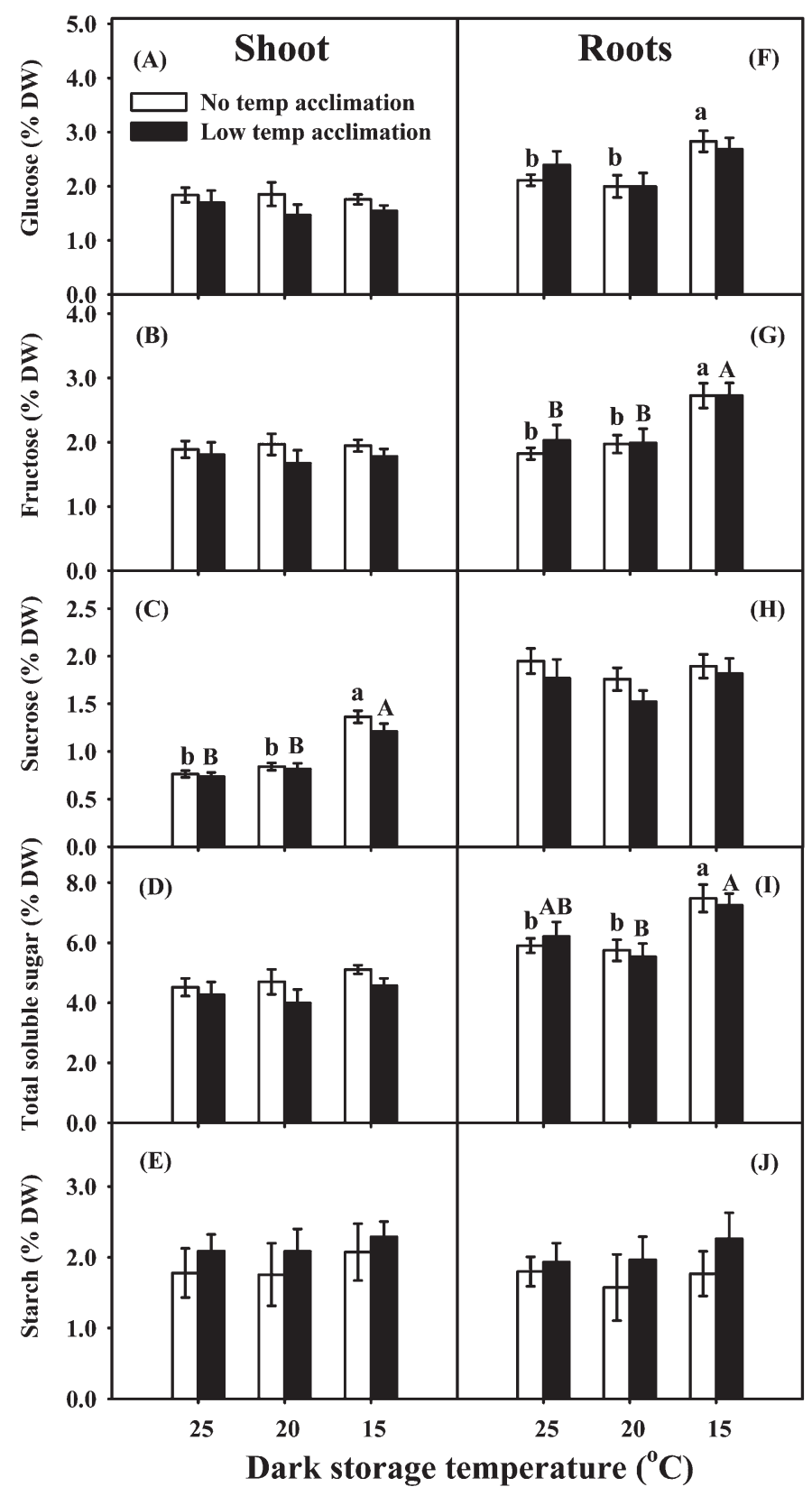

Fig. 6. Effects of temperature acclimatization before shipping and storage temperature on changes in carbohydrates in the shoot $(\mathbf{A}-\mathbf{E})$ and roots $(\mathbf{F}-\mathbf{J})$ of Phalaenopsis Sogo Yukidian 'V3'. Bars indicate the SE $(\mathrm{n}=6)$; columns with different capital or lowercase letters significantly differ $(P \leq 0.05)$ in dark storage temperature by least significant difference with or without preshipping lower temperature acclimation, respectively.

the main location of carbohydrate reserves is in the shoot (Fig. 2). Compared with newly matured leaves, blooming P. amabilis plants had higher concentrations of glucose and fructose in the flowers (Fig. 3A-B), indicating the strong sink strength of carbohydrates in the inflorescence. The priority of assimilate partitioning in monopodial orchids was described as usually decreasing in the order of inflorescences $>$ young leaves $>$ the shoot (Hew and Yong, 2004). Development of floral buds was accompanied by a progressive decrease in the starch concentration (Fig. 3E). On full flower opening, concentrations of glucose, fructose, and total soluble sugar were maximal (Figs. 3A, 3B, and 
3D). Hydrolysis of reserve carbohydrates to soluble sugars in floral buds could elevate the osmolarity of cell sap and promote water import, resulting in turgor changes and cell expansion (Hew and Yong, 2004). Research in Dendrobium crumenatum demonstrated similar results of decreases in starch and fructans and increases in soluble sugars in floral buds with increasing age (Yap et al., 2008). Differently, buds of the rose (Rosa hybrida) were reported to synthesize sucrose phosphate synthase to enhance importation of sucrose, and they gradually accumulated nonreducing sugars, sucrose, and starch during floral development (Kumar et al., 2007).

During postproduction, transferring potted plants from high to low irradiance limits the export of current assimilates from leaves to the flowers as a result of the severely reduced photosynthetic rate and reductions in the dry weight and carbohydrates in potted chrysanthemums (Trusty and Miller, 1991). However, according to our investigations, the dry weight of potted Phalaenopsis plants decreased very slowly during $40 \mathrm{~d}$ of SDS (data not shown). The net photosynthetic rate and stomata conductance of Phalaenopsis were close to zero during 7 to $21 \mathrm{~d}$ of SDS and rapidly recovered after being transferred to a greenhouse (Hou et al., 2010). According to this, we inferred that Phalaenopsis plants do not gain carbon from a source in the external environment during the long-term SDS but might maintain low metabolism to reduce energy consumption. Furthermore, carbohydrate analyses showed that starch decreased in the early period of SDS, which may infer a quick response of adaptation to the dark environment (Fig. 1E). With prolonged dark storage, the glucose and fructose in roots consecutively decreased during the $40 \mathrm{~d}$ of SDS, probably as a result of a limited carbohydrate supply from the shoot (Fig. 1A-B).

In this study, reductions of total soluble sugar and starch in Phalaenopsis leaves were more significant in reproductive plants than in vegetative plants during dark storage (Figs. 1D, 1E, 3D, and $3 \mathrm{E}$ ), which were attributed to a strong sink by the inflorescence. Dark storage resulted in a very low carbohydrate pool in leaves for exportation to inflorescences, which was associated with delayed floral bud development (Fig. 3). The youngest (F-8) bud of $P$. amabilis was susceptible to abortion after $7 \mathrm{~d}$ of dark storage, which was related to a reduction in the sucrose concentration (Fig. 3C). Respiration rate of the floral bud in Phalaenopsis Snow Mist 'Large Sepal' was substantially higher than a newly opened flower (Lee and Lin, 1992); similar results were also found in Lilium longiflorum 'Nellie White' (Wang and Breen, 1984). A high respiration rate of the youngest bud indicates high carbohydrate consumption; additionally, lower carbohydrate pool may be the reason for its high susceptibility to dark storage.

Substantial reduction in leaf starch was observed after $10 \mathrm{~d}$ of SDS; then the concentration remained at a constant level up to Day 40 (Fig. 1E). As a source of sucrose, glucose, and organic acid synthesis, starch probably provides the energy to maintain metabolism of Phalaenopsis in the dark. Also, Phalaenopsis leaves showed a pronounced day-night change in starch concentrations, which was highest at dusk and gradually decreased and reached a minimum at dawn (Chen et al., 2008). Therefore, inhibition of diurnal starch changes in the dark may also be a reason explaining the reductions in starch concentrations in the shoot and roots of Phalaenopsis in the first $10 \mathrm{~d}$ of SDS (Fig. 1E). In Aechmea 'Maya' plants, short-term (6 d) severe light limitation $\left(0.46 \mathrm{~mol} \cdot \mathrm{m}^{-2} \cdot \mathrm{d}^{-1} P P F\right)$ inhibited diurnal changes of net $\mathrm{CO}_{2}$ uptake and photosynthetic metabolites in young, fully developed leaves. However, when the severe light limitation was prolonged to $90 \mathrm{~d}$, photosynthetic diurnal changes reappeared but at lower magnitudes compared with normal plants, and the major storage carbon source shifted from starch to sucrose (Ceusters et al., 2011).

Wang (2007) reported that a 10-d lower temperature preshipping acclimation to $20{ }^{\circ} \mathrm{C}$ reduced the $\mathrm{CI}$ of Phalaenopsis after SDS at $15^{\circ} \mathrm{C}$, and similar results were observed in our study (Table 1). When exposed to low temperatures, Cucumis melo accumulated soluble sugars that elevated the tolerance to chilling stress (Michelle and Madore, 1992). Also, a lower nighttime temperature $\left(12^{\circ} \mathrm{C}\right)$ increased sucrose, stachyose, and galactinol levels in leaves of Cucumis sativa (Miao et al., 2007). In the current study, concentrations of sucrose in the shoot and of glucose and fructose in roots after $21 \mathrm{~d}$ of SDS were higher at a low temperature $\left(15^{\circ} \mathrm{C}\right)$ than those stored at 20 and $25^{\circ} \mathrm{C}$ (Figs. $6 \mathrm{C}, 6 \mathrm{~F}$, and $6 \mathrm{G})$. The results indicated that Phalaenopsis plants accumulated soluble sugars at low temperatures. Lower temperature acclimation at $25 / 20{ }^{\circ} \mathrm{C}$ (day/night) for $10 \mathrm{~d}$ reduced $\mathrm{CI}$ in Phalaenopsis caused by $21 \mathrm{~d}$ of SDS at $15^{\circ} \mathrm{C}$ (Table 1). However, no difference was found between carbohydrates of non-acclimated and lower-temperature acclimated plants, which may have been the result of the relatively high storage temperature or short duration of the acclimation (Fig. 6).

A storage temperature of $20^{\circ} \mathrm{C}$ preserved the quality of plants during simulated shipment, because no or very slight CI was observed in both temperature-acclimated and non-acclimated plants (Table 1). Also, we found that a shipping temperature of $25^{\circ} \mathrm{C}$ increased the number of yellowed leaves (Table 1 ). The incidence of CI was significant at $15^{\circ} \mathrm{C}$, and plants acclimated to a lower temperature before shipment could better withstand the effects of chilling (Table 1). Therefore, temperature acclimation of Phalaenopsis plants before shipment is highly recommended, because cultivars may have different susceptibilities to CI and plants may be subjected to a greater temperature drop in practice if they are grown in warmer greenhouses.

In conclusion, prolonged SDS resulted in the increase of yellowed leaves, which was associated with the reduction of total carbohydrates in vegetative Phalaenopsis. Moreover, a 10-d pre-shipping lower-temperature acclimation $\left(25{ }^{\circ} \mathrm{C}\right.$ day $/ 20{ }^{\circ} \mathrm{C}$ night) and a temperature of $20^{\circ} \mathrm{C}$ are recommended for long-term dark shipping of Phalaenopsis. To maintain good post-shipping performance, blooming Phalaenopsis should be stored at $20^{\circ} \mathrm{C}$ for less than $7 \mathrm{~d}$.

\section{Literature Cited}

Ceusters, J., A.M. Borland, C. Godts, E. Londers, S. Croonenborghs, D.V. Goethem, and M.P. De Proft. 2011. Crassulacean acid metabolism under severe light limitation: A matter of plasticity in the shadows? J. Expt. Bot. 62:283-291.

Chen, W.H., Y.C. Tseng, Y.C. Liu, C.M. Chuo, P.T. Chen, K.M. Tseng, Y.C. Yeh, M.J. Ger, and H.L. Wang. 2008. Cool-night temperature induces spike emergence and affects photosynthetic efficiency and metabolizable carbohydrate and organic acid pools in Phalaenopsis aphrodite. Plant Cell Rpt. 27:1667-1675.

Druege, U. and R. Kadner. 2008. Response of post-storage carbohydrate levels in pelargonium cutting to reduced air temperature during rooting and the relationship with leaf senescence and adventitious root formation. Postharvest Biol. Technol. 47:126-135.

Guo, W.J. and N. Lee. 2006. Effect of leaf and plant age, and day/night temperature on net $\mathrm{CO}_{2}$ uptake in Phalaenopsis amabilis var. formosa. J. Amer. Soc. Hort. Sci. 131:320-326.

Guy, C., F. Kaplan, and J. Kopka. 2008. Metabolomics of temperature stress. Physiol. Plant. 132:220-235. 
Hew, C.S. and J.W.H. Yong. 2004. The physiology of tropical orchids in relation to the industry. 2nd Ed. World Scientific, Singapore.

Hou, J.Y., T.L. Setter, and Y.C.A. Chang. 2010. Effects of simulated dark shipping on photosynthetic status and post-shipping performance in Phalaenopsis Sogo Yukidian 'V3'. J. Amer. Soc. Hort. Sci. 135:183-190.

Kataoka, K., K. Sumitomo, T. Fudano, and K. Kawase. 2004. Changes in sugar content of Phalaenopsis leaves before floral transition. Sci. Hort. 102:121-132.

Kumar, N., G.C. Srivastava, K. Dixit, A. Mahajan, and M. Pal. 2007. Role of carbohydrates in flower bud opening in rose (Rosa hybrida L.). J. Hort. Sci. Biotechnol. 82:235-242.

Lee, N. and Y.S. Lin. 1992. Respiration of Phalaenopsis flowers. J. Chinese Soc. Hort. Sci. 38:228-240 [in Chinese with English abstract].

McConnell, D.B. and T.J. Sheehan. 1978. Anatomical aspects of chilling injury to leaves of Phalaenopsis B1. HortScience 13:705706.

Miao, M., X.F. Xu, X.H. Chen, L.B. Xue, and B.S. Cao. 2007. Cucumber carbohydrate metabolism and translocation under chilling night temperature. J. Plant Physiol. 164:621-628.

Michelle, D.E. and M.A. Madore. 1992. Patterns of assimilate production and translocation in muskmelon (Cucumis melo L.). II. Low temperature effects. Plant Physiol. 99:966-971.
Motomura, H., O. Ueno, A. Kagawa, and T. Yukawa. 2008. Carbon isotope ratios and the variation in the diurnal pattern of malate accumulation in aerial roots of CAM species of Phalaenopsis (Orchidaceae). Photosynthetica 46:531-536.

Paul, M.J., S.P. Driscoll, and D.W. Lawlor. 1991. The effect of cooling on photosynthesis, amount of carbohydrate and assimilate export in sunflower. J. Expt. Bot. 42:845-852.

Rapaka, V.K., J.E. Faust, and J.M. Dole. 2008. Endogenous carbohydrate status affects postharvest ethylene sensitivity in relation to leaf senescence and adventitious root formation in Pelargonium cuttings. Postharvest Biol. Technol. 48:272-282.

Theron, K.I. and G. Jacobs. 1996. Changes in carbohydrate composition of the different bulb components of Nerine bowdenii W. Watson (Amaryllidaceae). J. Amer. Soc. Hort. Sci. 121:343-346.

Trusty, S.E. and W.B. Miller. 1991. Postproduction carbohydrate levels in pot chrysanthemums. J. Amer. Soc. Hort. Sci. 116:1013-1018.

Wang, Y.T. 2007. Temperature, duration in simulated shipping, and thermal acclimatization on the development of chilling injury and subsequent flowering of Phalaenopsis. J. Amer. Soc. Hort. Sci. 132:202-207.

Wang, Y.T. and P.J. Breen. 1984. Respiration and weight changes of Easter lily flowers during development. HortScience 19:702-703.

Yap, Y.M., C.S. Loh, and B.L. Ong. 2008. Regulation of flower development in Dendrobium crumenatum by changes in carbohydrate contents, water status and cell wall metabolism. Sci. Hort. 119:59-66. 